\title{
Change in Relationship between the East Asian Winter Monsoon and the East Asian Jet Stream during the 1998-99 Regime Shift
}

\author{
SE-YONG SONG AND SANG-WOOK YeH \\ Department of Marine Sciences and Convergence Technology, Hanyang University, Ansan, South Korea \\ JAE-HEUNG PARK \\ Division of Environmental Science and Engineering, Pohang University of Science and \\ Technology (POSTECH), Pohang, South Korea
}

(Manuscript received 10 December 2018, in final form 4 June 2019)

\begin{abstract}
A composite analysis was conducted on the reanalysis dataset for 1979-2016, along with an idealized model experiment to show that the relationship between the East Asian jet stream (EAJS) and the East Asian winter monsoon (EAWM) is nonstationary. The relationship between EAWM and the EAJS weakened during the late 1990s. This decadal change in the EAJS-EAWM relationship was mainly due to a change in the secondary circulation across the EAJS between two contrasting periods, induced by the northward shift of the EAJS. A possible mechanism associated with the decadal change in meridional displacement of the EAJS is proposed. The enhanced convective activity in the western tropical Pacific after the late 1990s results in stronger Hadley circulation that could have contributed to the northward displacement of the Hadley circulation boundary latitude. Subsequently, this leads to the northward shift of the EAJS. Therefore, it is necessary to define a new EAJS index to account for the EAWM variability based on the change in the oceanic and atmospheric mean state across the late 1990s.
\end{abstract}

\section{Introduction}

The East Asian winter monsoon (EAWM) is one of the most active climate systems in the Northern Hemisphere (Lau and Li 1984; Zhang et al. 1997; Wang et al. 2000). The EAWM not only affects the temperature via dry and cold northwesterly winds in East Asia but also influences the weather and climate in remote areas (Chang and Lau 1982; Wen et al. 2000; Chan and Li 2004; Chang et al. 2011; Ma et al. 2018). For example, Chang et al. (2011) argued that the EAWM can induce deep convection over the Maritime Continent due to the intrusion of cold air from the extratropics. Ma et al. (2018) also showed that the EAWM influences circulation variability and rainfall related to El Niño-Southern Oscillation (ENSO), and influences the North American climate anomalies by modulating ENSO-related teleconnections. In addition, EAWM variability can induce significant social and economic damage (Wang et al. 2011; Huang et al.

Corresponding author: Sang-Wook Yeh, swyeh@hanyang.ac.kr
2012). Therefore, the understanding of the EAWM variability and its mechanism has been widely discussed in the climate literature (Webster et al. 1998; Huang et al. 2003; Chang et al. 2006; Wang et al. 2010; Ha et al. 2012; Wang and Lu 2017; Miao et al. 2018).

The EAWM structure varies from the lower troposphere to the tropopause in a large meridional domain. When the EAWM is strong, the Siberian high (SH) and Aleutian low (AL) induce strong northwesterly winds toward East Asia in the lower troposphere. In addition, both the East Asian trough (EAT) and the East Asian jet stream (EAJS) around the coast of East Asia are enhanced in the midtroposphere and upper troposphere, respectively. These planetary-scale three-dimensional circulations, associated with the EAWM variability, are inherently linked to each other (Ding and Krishnamurti 1987; Sun and Li 1997; Jhun and Lee 2004; Wang et al. 2009; Li and Yang 2010; Park et al. 2012). The EAJS is characterized by strong and narrow westerly winds in the extratropics, including East Asia and the Pacific (Krishnamurti 1961; Cressman 1984; Yang et al. 2002), which significantly 
affect weather and local climate anomalies in East Asia as well as over the remote regions in its downstream (Reiter 1963; Kang 1990; Yang et al. 2002). The stronger EAJS in its core region is related to the anomalous cyclonic vorticity over East Asia and deep EAT. Such a circulation is associated with strong EAWM features, including strong SH and prevailing northerly winds, along with cold temperatures in East Asia. Therefore, the variability of the EAJS is closely associated with variability in the EAWM (Yang et al. 2002; Jhun and Lee 2004; Li and Yang 2010). The intensity of EAJS was found to be significantly correlated with EAWM (Yang et al. 2002).

However, not much study has been conducted on the nonstationary relationship of the EAWM and the EAJS. Hence, the nonstationary relationship between the EAJS and the EAWM was examined for 1979-2016. This study particularly focused on variations in the relationship between the EAWM and the EAJS during a regime shift during the winter of the 1998-99 over the North Pacific region. The 1998-99 regime shift, which may have resulted from several mechanisms, including internal air-sea interactions within the Pacific (Hong et al. 2014), a cooling in the Bering Sea (Minobe 2002), slow oceanic dynamic adjustments (Jo et al. 2013), and the mean state change in the tropical Pacific (Jo et al. 2014), is characterized by a dipole-like structure of sea surface temperature (SST) anomalies in the North Pacific along $40^{\circ} \mathrm{N}$, where significant warming is prominent in the southwestern and central North Pacific. It is also known that the 1998-99 regime shift was associated with the decadal North Pacific SST pattern, manifested in phenomena such as the Pacific decadal oscillation (PDO) (Minobe 2002; Jo et al. 2013; Hong et al. 2014; Lyon et al. 2014), which influenced the climate anomalies in East Asia on low-frequency time scales (Zhou et al. 2007; Wang et al. 2008; Ding et al. 2014; Sun et al. 2016; Chen et al. 2018). In this study, variations in the relationship between the EAJS and the EAWM across the 1998-99 regime shift were examined, along with the associated mechanism.

The remainder of the paper is organized as follows. Section 2 describes the datasets and methods used in this study. Section 3 shows the decadal change in the relationship between the EAJS and the EAWM, and its possible mechanisms are discussed. The summary and discussion are given in section 4.

\section{Data and method}

Multiple observational datasets for the period of December 1979 to February 2017 were used. The atmospheric variables were obtained from the monthly mean National Centers of Environmental Prediction-
National Center for Atmospheric Research reanalysis dataset on a $2.5^{\circ} \times 2.5^{\circ}$ grid (Kalnay et al. 1996). The oceanic data were taken from the monthly mean $2^{\circ} \times 2^{\circ}$ gridded Extended Reconstruction Sea Surface Temperature, version 5 (ERSST.v5) (Huang et al. 2017). The precipitation and outgoing longwave radiation (OLR) data were used as a proxy for convective activity. For precipitation, the monthly Climate Prediction Center Merged Analysis of Precipitation on a $2.5^{\circ} \times 2.5^{\circ}$ grid (Xie and Arkin 1997) was used. The monthly OLR dataset used here was obtained from High Resolution Infrared Radiation Sounder with a $2.5^{\circ} \times 2.5^{\circ}$ grid (Lee et al. 2007).

As reviewed by Wang and Chen (2010), the EAWM is often defined by four aspects (i.e., jet stream, surface wind, EAT, and the large-scale land-sea thermal contrast). Therefore, the following climate indices associated EAWM were used: 1) the EAJS index (EAJSI), defined as the $200-\mathrm{hPa}$ zonal wind averaged within the domain of $30^{\circ}-35^{\circ} \mathrm{N}$ and $130^{\circ}-160^{\circ} \mathrm{E}$ (Yang et al. 2002) and 2) three EAWM indices (EAWMI, EAWMI-1, and EAWMI-2). EAWMI is defined as the 850-hPa meridional wind averaged within $20^{\circ}-40^{\circ} \mathrm{N}$ and $100^{\circ}-140^{\circ} \mathrm{E}$ (Yang et al. 2002). EAWMI-1 is defined as the 500-hPa geopotential height $(\mathrm{GPH})$ averaged within $25^{\circ}-45^{\circ} \mathrm{N}$ and $110^{\circ}-145^{\circ} \mathrm{E}$, where the EAT is located and can represent the EAWM-related circulation and temperature variability (Wang et al. 2009; He and Wang 2013). On the other hand, EAWMI-2 represents the largescale land-sea thermal contrast in East Asia, as defined below:

$$
\text { EAWMI-2 }=\left(2 \times \mathrm{SLP}_{1}-\mathrm{SLP}_{2}-\mathrm{SLP}_{3}\right) / 2,
$$

where $\mathrm{SLP}_{1}, \mathrm{SLP}_{2}$, and $\mathrm{SLP}_{3}$ indicate the normalized SLP averaged in Siberia $\left(40^{\circ}-60^{\circ} \mathrm{N}, 70^{\circ}-120^{\circ} \mathrm{E}\right)$, North Pacific $\left(30^{\circ}-50^{\circ} \mathrm{N}, 140^{\circ} \mathrm{E}-170^{\circ} \mathrm{W}\right)$, and the Maritime Continent $\left(20^{\circ} \mathrm{S}-10^{\circ} \mathrm{N}, 110^{\circ}-160^{\circ} \mathrm{E}\right)$, respectively (Wang and Chen 2014).

Note that a positive (negative) index of the EAWM indicates a strong (weak) monsoon in the EAWMI and EAWMI-1. In this study, the seasonal mean data during the boreal winter [December-January-February (DJF)] were used (e.g., the term 1997 denotes 1997D/ 1998JF). The seasonal means were calculated from the monthly data from the winter season and the seasonal anomalies were obtained by subtracting the seasonal means from the total winter-mean fields. Unless stated otherwise in the text, the results correspond to the winter season. The two-tailed Student's $t$ test was used as the statistical significance test. The regime shift analysis was used to identify shift in the climate regime (Rodionov 2004). 
(a) [1979-2016 DJF] Climatological U200 [m/s]

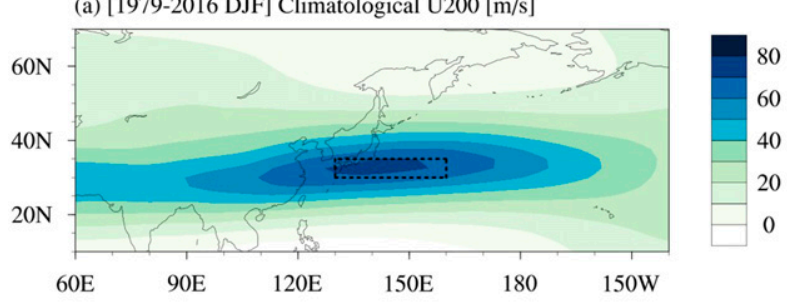

(b) EAJS Intensity Index [m/s]

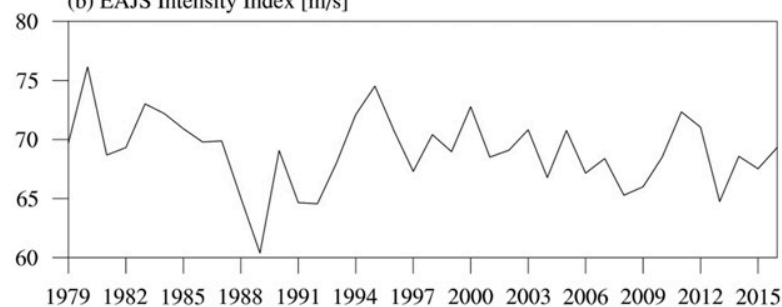

FIG. 1. (a) Climatological DJF-mean 200-hPa zonal wind (U200) distribution (shading, $\mathrm{m} \mathrm{s}^{-1}$ ) between 1979 and 2016. The dashed line indicates the jet core region $\left(30^{\circ}-35^{\circ} \mathrm{N}, 130^{\circ}-160^{\circ} \mathrm{E}\right)$ used to compute the EAJS index. (b) Time series of the EAJSI during DJF for the period 1979-2016.

\section{Results}

a. Change in the relationship of EAJS-EAWM across the late 1990s

Figure 1a shows the structure of the EAJS, which is characterized by narrow and strong westerly winds in the upper troposphere. The region between $30^{\circ}-35^{\circ} \mathrm{N}$ and $130^{\circ}-160^{\circ} \mathrm{E}$ was defined as the jet core region. Figure $1 \mathrm{~b}$ displays the time series of the EAJSI. The variability of the EAJS intensity has a strong interannual behavior, with peak spectral variance at 3-4 years (figure not shown), which is also closely linked to the EAWM through a positive feedback (Yang et al. 2002; Jhun and Lee 2004; Li and Yang 2010), i.e., a stronger EAJS in its core region is related to the anomalous cyclonic vorticity in association with deep EAT. Such circulation is associated with strong EAWM features, including a strong $\mathrm{SH}$ and prevailing northerly winds, along with cold temperatures, in East Asia. This positive feedback leads to a statistically significant correlation at the $99 \%$ confidence level between the
EAWMI and the EAJSI (i.e., 0.56) (Table 1). A statistically significant correlation of 0.62 at $99 \%$ confidence levels was also found between the EAWMI-1 and the EAJSI (Table 1).

To determine the temporal change in the relationship between the EAJS and EAWM, a regime shift analysis was conducted based on the 15-yr moving correlation coefficient between the EAJSI and the three EAWM indices. Figure 2 shows that a significant change in the relationship between the EAJS and the EAWM occurred across the late 1990s, irrespective of the EAWM index being used. Before the late 1990s, the intensity of the EAJS was strongly correlated with the EAWM. However, the strength of correlation between the EAJSI and the EAWMI started weakening after the late 1990s. Table 1 shows the nonstationary relationship between the EAJS and the EAWM, both before and after the late 1990s, and an almost identical nonstationary connection was detected in the other EAWM indices (i.e., EAWMI-1 and EAWMI-2). While the EAJSI was significantly correlated with the EAWMI during 1979-97 ( $r=0.71$, here $r$ is the simultaneous correlation coefficient), the correlation was insignificant during 1998-2016 $(r=0.20)$. These results indicate that the EAJS-EAWM connections have apparently weakened since the late 1990s. Therefore, two distinct periods were defined: the period of a strong EAJS-EAWM relationship during 1979-97 (hereafter, P1) and the period of a weak EAJS-EAWM relationship during 1998-2016 (hereafter, P2).

To verify the EAJS-EAWM correlation, the composite pattern for the difference between strong and weak EAJS years was conducted for P1 and P2 for the 850-hPa winds and surface air temperature, respectively (Fig. 3). Strong EAJS years were defined as the years when the standard deviation in EAJSI was greater than 0.75 for $\mathrm{P} 1$ and $\mathrm{P} 2$, respectively. In contrast, weak EAJS years were defined as the years when the standard deviation in EAJSI was less than -0.75 for $\mathrm{P} 1$ and $\mathrm{P} 2$, respectively (Table 2 ). There was only a minor variation in results between strong and weak EAJS index when a 0.5 standard deviation was used (figure not shown). During P1, significant northwesterly winds and cold surface air temperature anomalies were dominant in

TABLE 1. Correlation coefficients of the EAJSI with the EAWMI, EAWMI-1, and EAWMI-2 for P1, P2, and the total period.

\begin{tabular}{cccc}
\hline \hline Correlation with EAJSI & P1 (1979-97) & P2 (1998-2016) & Total (1979-2016) \\
\hline EAWMI & $0.71^{\mathrm{a}}$ & 0.20 & $0.56^{\mathrm{a}}$ \\
EAWMI-1 & $0.76^{\mathrm{a}}$ & 0.27 & $0.62^{\mathrm{a}}$ \\
EAWMI-2 & $0.86^{\mathrm{a}}$ & 0.40 & $0.67^{\mathrm{a}}$ \\
\hline
\end{tabular}

\footnotetext{
${ }^{\text {a }}$ Correlation significant at the $99 \%$ confidence levels.
} 
(a) EAJSI-EAWMI 15-year Moving Correlations

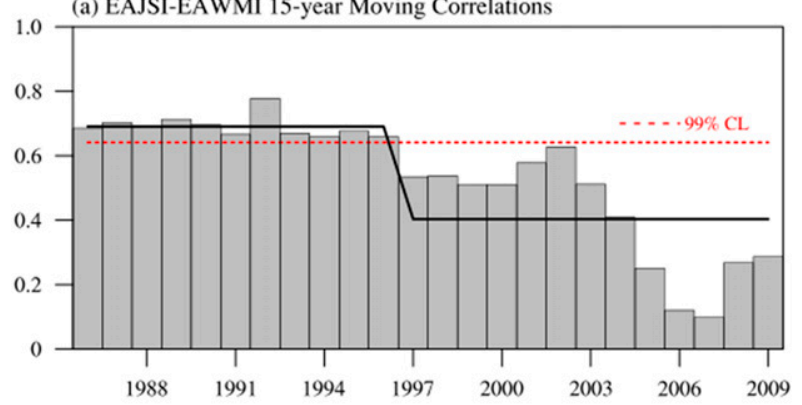

(b) EAJSI-EAWMI-1 15-year Moving Correlations

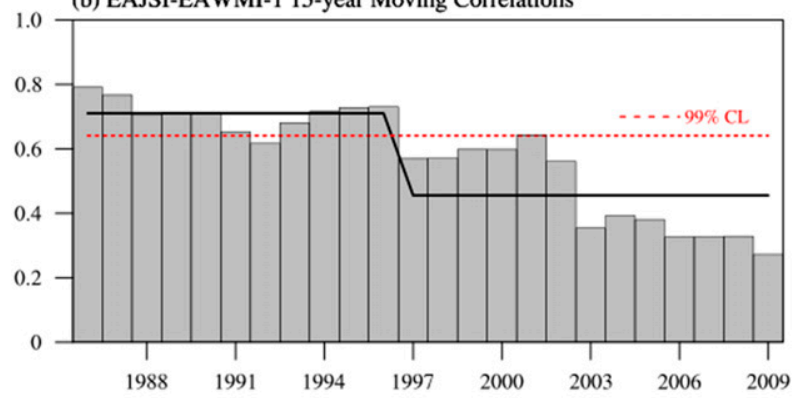

(c) EAJSI-EAWMI-2 15-year Moving Correlations

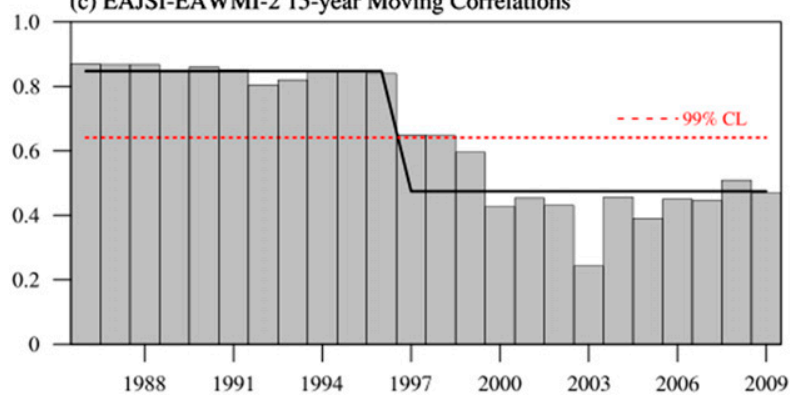

FIG. 2. (a) 15-yr running correlation coefficient (gray bar) between the EAJSI and the EAWMI. The black line denotes the mean value for the periods before and after the significant regime shifts, based on Rodionov (2004). For determining the regime shift, the following parameters were used: cutoff length $=15$; probability level $=0.1$; and Huber's weight parameter $=1.5$. The horizontal dotted red line indicates the $99 \%$ confidence level, with a constant degree of freedom equal to 13. (b), (c) As in (a), but for the correlation with EAWMI-1 and EAWMI-2, respectively.

East Asia (Figs. 3a,b), which were not seen during P2 (Figs. 3c,d). This indicates that the variability in the EAJS intensity does not account for the northwesterly winds and cold surface air temperature anomalies associated with the EAWM variability since the late 1990s, which is consistent with results presented in Fig. 2. Therefore, it can be inferred that the positive feedback between the EAWM and the EAJS also weakened from $\mathrm{P} 1$ to $\mathrm{P} 2$. There is a possibility that the strengthening of the EAJS lags that of the SH (Song et al. 2016). However, the strong EAJS core since the late 1990s was not associated with an enhanced EAT, including the prevailing northerly winds and cold surface air temperatures in East Asia (figure not shown).

\section{b. Physical processes associated with a weakening of} the EAJS and the EAWM after the late 1990s

To understand the physical processes associated with a weakening of the relationship between the EAJS and the EAWM, the changes of the EAJS variability were assessed, followed by an examination of the changes in the atmospheric and oceanic variables associated with the EAJS variability between P2 and P1, respectively.

The variability of EAJS was found to have decreased from P1 to P2. One standard deviation of the EAJSI during P1 was $3.78 \mathrm{~m} \mathrm{~s}^{-1}$, which was larger than that during P2 $\left(2.23 \mathrm{~m} \mathrm{~s}^{-1}\right)$. In addition, the dominant time scales of EAJS variability reduced from 3-4 years to about 2 years (figure not shown). Figures $4 \mathrm{a}-\mathrm{c}$ display the composite pattern of 300-hPa GPH, OLR, and SST between strong and weak EAJS years (strong EAJS years minus weak EAJS years) during P1. Figures $4 d-f$ present the same information for $\mathrm{P} 2$. The overall pattern of $300-\mathrm{hPa}$ GPH around East Asia and OLR anomalies in the tropics, which were associated with the EAJS variability, was not significantly different between $\mathrm{P} 1$ and $\mathrm{P} 2$. In both the periods, a strong cyclonic circulation was located around East Asia (Figs. 4a,d) and enhanced convection anomalies were observed in the western tropical Pacific (Figs. $4 \mathrm{~b}, \mathrm{e})$ during the strong EAJS years as compared to the weak EAJS years. In addition, the anomalous SST was characterized by a cooling effect in the central-toeastern tropical Pacific during both periods (Figs. 4c,f), which is consistent with the structure of anomalous OLR.

However, subtle differences were found between the two contrasting periods. For example, a center of cyclonic circulation associated with strong EAJS was shifted northward during P2 as compared to P1 (Figs. $4 \mathrm{a}, \mathrm{d})$, which is consistent with the northward shift of the anomalous cool SST in the western North Pacific. Furthermore, a center of negative OLR anomalies in the western tropical Pacific had a slight northward shift during P2 as compared to P1 (Figs. 4b,e). Therefore, it was inferred that the mean position of EAJS and its associated atmospheric variability shifted northward from P1 to P2.

It is known that the change in the relationship of climate variables and indices is mainly explained by the interdecadal change in the background state of the coupled ocean-atmosphere system (Chang et al. 2000; Polyakova et al. 2006; Wang et al. 2008; Ding et al. 2010; 
(a) [Strong-Weak] UV850 in P1

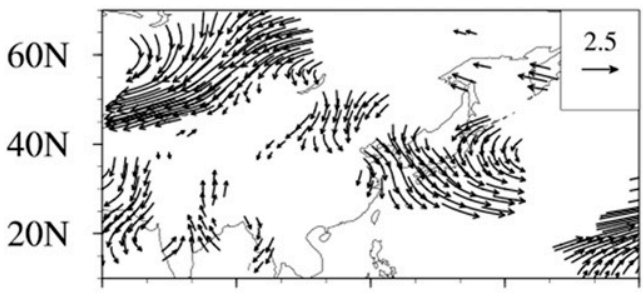

(b) [Strong-Weak] SAT in P1

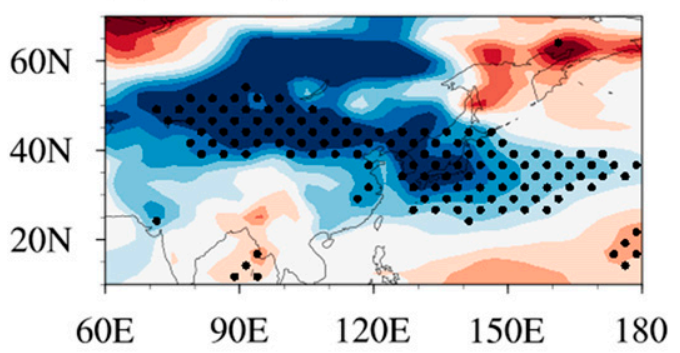

(c) [Strong-Weak] UV850 in P2

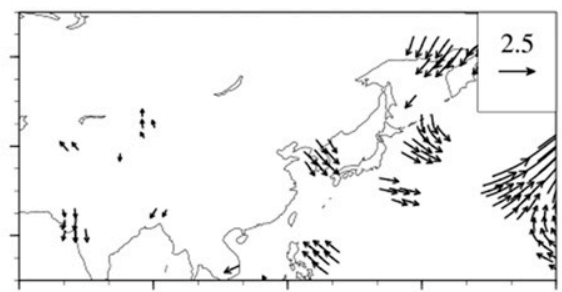

(d) [Strong-Weak] SAT in P2

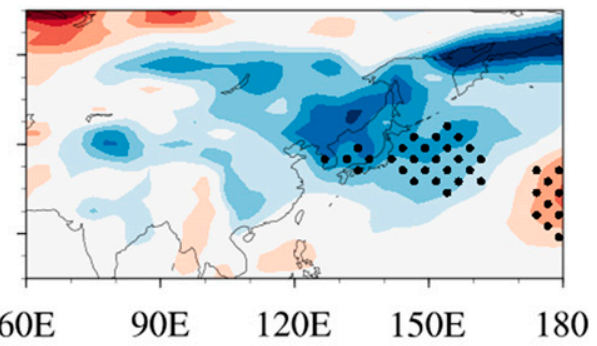

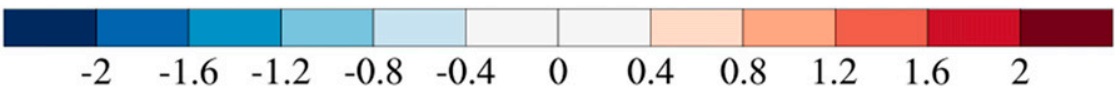

FIG. 3. The composite pattern of the (a) 850-hPa winds (vector, $\mathrm{m} \mathrm{s}^{-1}$ ) and (b) surface air temperatures (shading, K) for strong minus weak EAJSI in P1. (c),(d) As in (a),(b), respectively, but for P2. The black dots indicate the areas significant at the $95 \%$ confidence levels.

Gong et al. 2018; Wang et al. 2019). The differences in atmospheric circulation between the two periods were also analyzed. A significant increase (decrease) in the 200-hPa zonal wind was observed in the northern part (southern) of the EAJS core region (Fig. 5a). Consistently, the anomalous high GPH at $500 \mathrm{hPa}$ and sea level pressure with a barotropic structure was observed in the central-to-eastern North Pacific, where the EAJS exits (Figs. 5b,c). In addition, a baroclinic structure of 500-hPa GPH and sea level pressure in South Asia was also associated with the northward shift of EAJS from $\mathrm{P} 1$ to $\mathrm{P} 2$. This indicates that the center of the EAJS shifted northward in P2 as compared to that in P1, which could have caused the change in the meridional structure of the secondary circulation across the EAJS around East Asia from P1 to P2 (Kim et al. 2016). In other words, a modulation in the secondary circulation induced by the meridional shift of the EAJS may have led to a change in the meridional wind associated with the EAWM over East Asia. Subsequently, it may have led to a change in the relationship between the EAJS and the EAWM.

The changes in the atmospheric circulation associated with a northward shift in the EAJS could have caused the change in the EAJS-EAWM relationship during the two periods. Hence, the change in the meridional circulation anomalies associated with the EAJSI from $\mathrm{P} 1$ to $\mathrm{P} 2$ was assessed. Figures $6 \mathrm{a}$ and $6 \mathrm{c}$ show the correlation maps of the zonal mean $\left(100^{\circ}-140^{\circ} \mathrm{E}\right)$ zonal wind with the EAJSI in P1 and P2. Note that the zonal mean over $100^{\circ}-140^{\circ} \mathrm{E}$ was selected to identify the variability in the secondary circulation across the EAJS over East Asia. A maximum correlation coefficient between the zonal-mean zonal wind anomalies and

TABLE 2. List of strong and weak EAJS event years (1979-2016) used in the composite.

\begin{tabular}{lcc}
\hline & P1 & P2 \\
\hline Strong EAJS & $1980,1983,1984,1994,1995$ & $2000,2003,2005,2011,2012$ \\
Weak EAJS & $1988,1989,1991,1992$ & $2004,2006,2008,2009,2013$ \\
\hline
\end{tabular}


(a) [Strong-Weak] GPH300 in P1

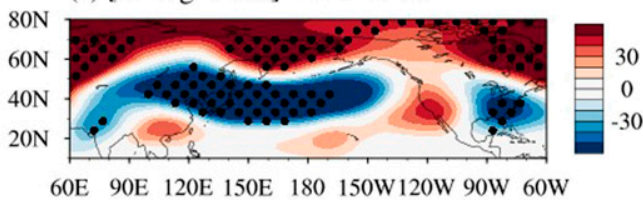

(b) [Strong-Weak] OLR in P1

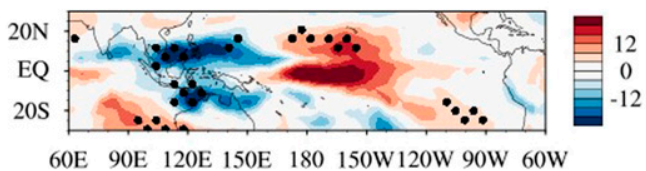

(c) [Strong-Weak] SST in P1

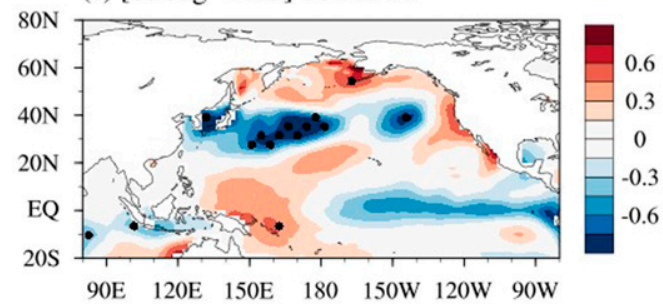

(d) [Strong-Weak] GPH300 in P2

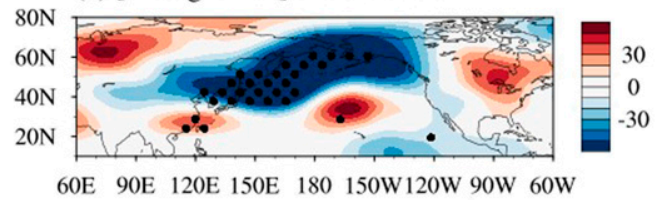

(e) [Strong-Weak] OLR in P2

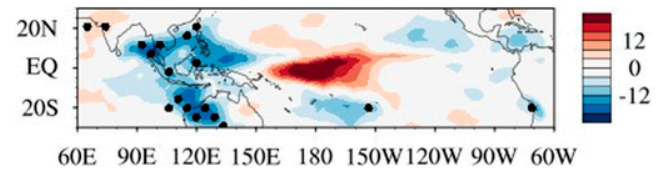

(f) [Strong-Weak] SST in P2

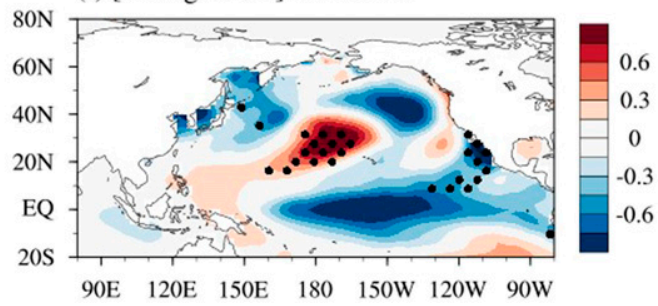

FIG. 4. (a),(d) Composite pattern of the 300-hPa geopotential height (shading, $\mathrm{m}$ ) for strong minus weak EAJSI in P1 and P2, respectively. (b),(e);(c),(f) As in (a),(d), but for the OLR (shading, $\mathrm{W} \mathrm{m}^{-2}$ ) and SST (shading, K), respectively. The black dots indicate the areas significant at the $95 \%$ confidence levels.

EAJS variability was observed at the upper levels (near $30^{\circ} \mathrm{N}$ ) during P1 (Fig. 6a). During P2, however, the region where the maximum correlation coefficient was observed at the upper level shifted northward near $35^{\circ} \mathrm{N}$ (Fig. $6 \mathrm{c}$ ). This implies that the variability in the zonal-mean zonal wind associated with the variability in the EAJS shifted to the north in P2, which is associated with the northward shift of the EAJS in P2 as compared to P1 (Fig. 5). Subsequently, it was found that the zonal mean $\left(100^{\circ}-140^{\circ} \mathrm{E}\right)$ meridional circulation anomalies, which are associated with the EAJS variability, were also different between $\mathrm{P} 1$ and P2 (Figs. 6b,d). During P1, the meridional circulation anomalies over East Asia were significantly correlated with the EAJSI. In particular, the strongly correlated lower-troposphere meridional wind anomalies showed a strong EAJS-EAWM relationship, indicating that a strong EAJS led to the prevailing northerly winds, causing cold surface air temperatures in East Asia (see Figs. 3a,b). During P2, in contrast, the meridional circulation anomalies over East Asia were not significantly correlated with the EAJSI, leading to a weakening of the EAJS-EAWM relationship.

Hence, there is a need to study the processes that caused the northward shift of EAJS from P1 to P2. It is known that the EAJS, which is located at the poleward boundary of the Hadley circulation, is driven by the upper-tropospheric angular momentum transport through thermally direct meridional overturning circulation (Held and Hou 1980; Lindzen and Hou 1988). Furthermore, a previous study found a significant positive connection between the western tropical convection and the meridional location of the local Hadley cell boundary (Park and An 2014). They argued that strong convection in the western tropical Pacific induces the northward expansion of the local Hadley circulation, leading to the northward shift in the EAJS, since its meridional displacement has a positive relationship with the northern edge of the local Hadley circulation. Therefore, the local Hadley circulation over the western tropical Pacific could have influenced the meridional location of the EAJS, especially during the boreal winter.

To examine this phenomenon, the decadal change in convective activity in the western tropical Pacific across the 1998-99 regime shift was assessed. An increase in precipitation in the western tropical Pacific was observed in P2 along with an enhanced OLR (Figs. 7a,b). This is indicative of an intensification in convective activity and Hadley circulation over the western tropical Pacific from P1 to P2. The Hadley circulation boundary latitude (HCBL) was also calculated, which is 
(a) U200 [P2-P1] (shading), [P1] (contour)

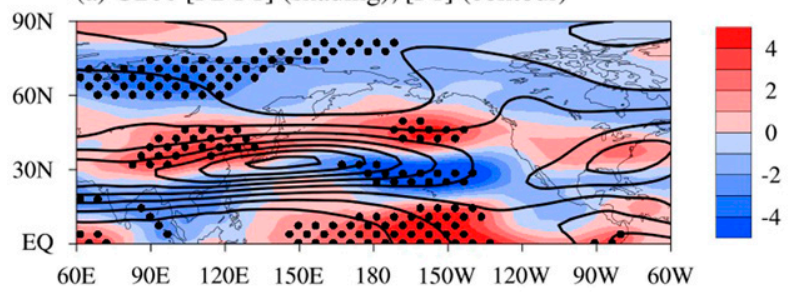

(b) GPH500 [P2-P1] (shading), [P1] (contour)

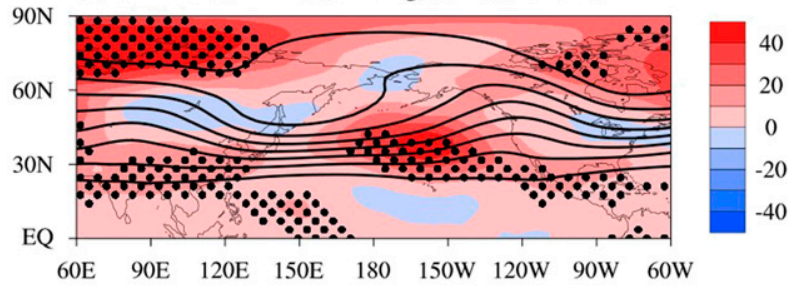

(c) SLP [P2-P1] (shading), [P1] (contour)

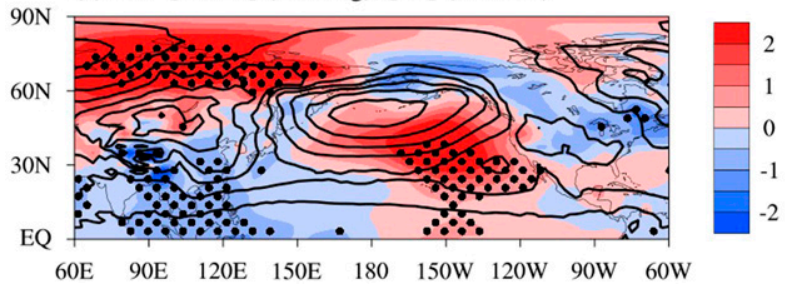

FIG. 5. (a) Climatological DJF-mean 200-hPa zonal wind distribution (contour, $\mathrm{m} \mathrm{s}^{-1}$ ) for P1. DJF-mean 200-hPa zonal wind difference between P2 and P1 (shading, $\mathrm{m} \mathrm{s}^{-1}$ ). The black dots indicate the areas significant at the $95 \%$ confidence levels. (b),(c) As in (a), but for the 500-hPa geopotential height and sea level pressure, respectively. Contour intervals are $10 \mathrm{~m} \mathrm{~s}^{-1}$ for 200$\mathrm{hPa}$ zonal wind, $100 \mathrm{~m}$ for $500-\mathrm{hPa}$ geopotential height, and $4 \mathrm{hPa}$ for sea level pressure.

defined as the position where the maximum decreases in the zonal mean $\left(90^{\circ}-130^{\circ} \mathrm{E}\right)$ tropopause height in the meridional direction in the $20^{\circ}-40^{\circ} \mathrm{N}$ band (Park and An 2014). Figure 8 shows the time series of HCBL and the western tropical Pacific convective activity (WPCA) index for 1979-2016. Note that the WPCA index is defined as the winter mean precipitation averaged for $5^{\circ} \mathrm{S}-20^{\circ} \mathrm{N}$ and $90^{\circ}-130^{\circ} \mathrm{E}$, which represents the convective activity in the western tropical Pacific (Fig. 7). The simultaneous correlation coefficient between the HCBL and WPCA index was 0.82 , which was statistically significant at $99 \%$ confidence levels. This indicates that the intensity of convective activity in the western tropical Pacific is closely associated with the north-south displacement of local Hadley circulation. Furthermore, it was found that the HCBL shifted northward across the late 1990s, which is consistent with stronger convective activity in the western tropical Pacific (Figs. 7 and 8). Therefore, stronger Hadley circulation due to the enhanced convective activity in the western tropical Pacific across the late 1990s could have contributed to the northward displacement of the HCBL, subsequently leading to the northward shift of the EAJS during P2.

To further highlight the effect of the western tropical Pacific heating on the displacement of the EAJS, an idealized experiment was conducted using the Linear Baroclinic Model (LBM) with horizontal resolution of T42 and 20 vertical levels (Watanabe and Kimoto 2000). The LBM is a time-dependent spectral model based on the primitive equations linearized for the atmospheric background state. In this idealized experiment, an atmospheric background state and an idealized heating with its vertical profile over the western tropical Pacific (Fig. 9a) were defined based on the differences of OLR between P1 and P2 (Fig. 7). Note that the maximum of atmospheric convective heating rate difference between P1 and P2, obtained by analyzing the JRA-55 reanalysis dataset (Kobayashi et al. 2015), was observed near $300 \mathrm{hPa}$ (figure not shown). The steady atmospheric response obtained by averaging the last 20 days from the 30-day LBM simulation was then analyzed. Figure $9 \mathrm{~b}$ displays the zonal mean $\left(100^{\circ}-140^{\circ} \mathrm{E}\right)$ zonal wind at $200 \mathrm{hPa}$ in response to heating over the western tropical Pacific. The zonal mean zonal wind was found to increase (decrease) in the northern (southern) part of climatological EAJS in East Asia, indicating that the EAJS shifted northward. Therefore, it can be concluded that the atmospheric heating over the western tropical Pacific (Fig. 7) contributed to the northward displacement of the EAJS during P2.

\section{Discussion and summary}

The nonstationary relationship of EAJS-EAWM could have been caused by three reasons: the change in the variability of the EAJS, the change in the variability of EAWM, and both. In this study, the decadal change in the relationship between the EAJS and the EAWM across the late 1990s was assessed, along with the possible mechanisms associated with changes in the EAJS.

This study found that while the EAJS had a significant relationship with the EAWM during P1 (1979-97), it had an insignificant relationship with the EAWM during P2 (1998-2016). Decadal change in the EAJS-EAWM relationship could be explained by the change in the secondary circulation associated with the northward shift of the EAJS between the two contrasting periods. Before the late 1990s, the secondary circulation around the EAJS was strongly correlated with the meridional winds over the core region of the East Asian monsoon, 
(a) Zonal Mean U in P1

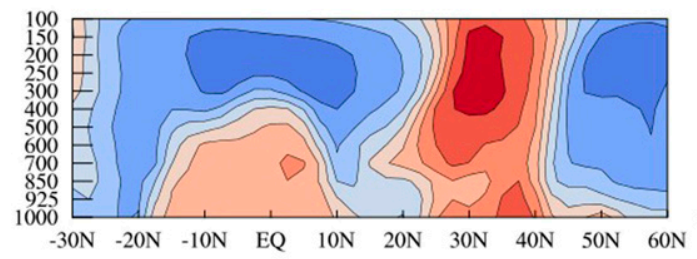

(b) Zonal Mean Meridional Circulation in P1

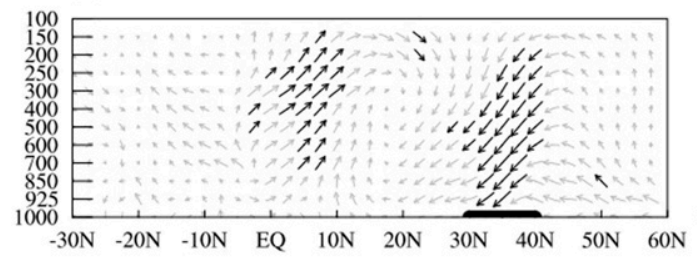

(c) Zonal Mean U in P2

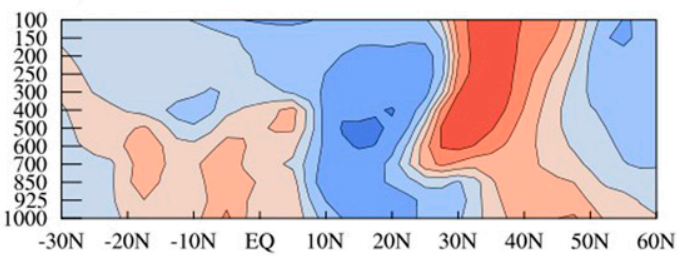

(d) Zonal Mean Meridional Circulation in P2

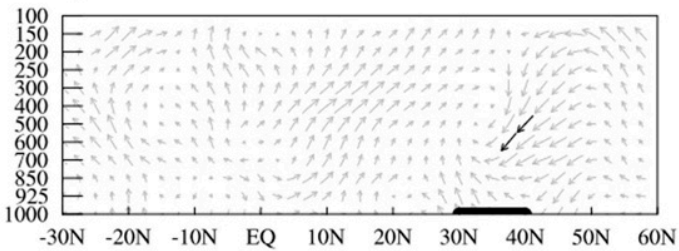

\section{$\begin{array}{lllllllll}-0.8 & -0.6 & -0.4 & -0.2 & 0 & 0.2 & 0.4 & 0.6 & 0.8\end{array}$}

FIG. 6. (a) The correlation map of zonal mean $\left(100^{\circ}-140^{\circ} \mathrm{E}\right)$ zonal wind against EAJSI in P1. (b) DJF correlation vectors of zonal mean $\left(100^{\circ}-140^{\circ} \mathrm{E}\right)$ meridional circulation against EAJSI in P1. (c),(d) As in (a),(b), respectively, but for P2. In (b) and (d), the black arrows show significance at the $95 \%$ confidence levels and the black bold line indicates the East Asian region.

which induced a significant relationship between the EAJS and the EAWM. On the other hand, during P2, the secondary circulation related to the northward shift of the EAJS is uncorrelated with surface meridional winds over East Asia, resulting in the weakening of the EAJS-EAWM relationship. In other words, the change in the secondary circulation across the EAJS core favored significant (insignificant) EAJS-related lower tropospheric winds over East Asia in P1 (P2), leading to the changes in the EAJS-EAWM relationship. Further investigation showed that the decadal change in the meridional position in the EAJS was associated with intensified convective activity in the western tropical Pacific after the late 1990s. An enhanced

(a) Precipitation Difference [P2 minus P1]

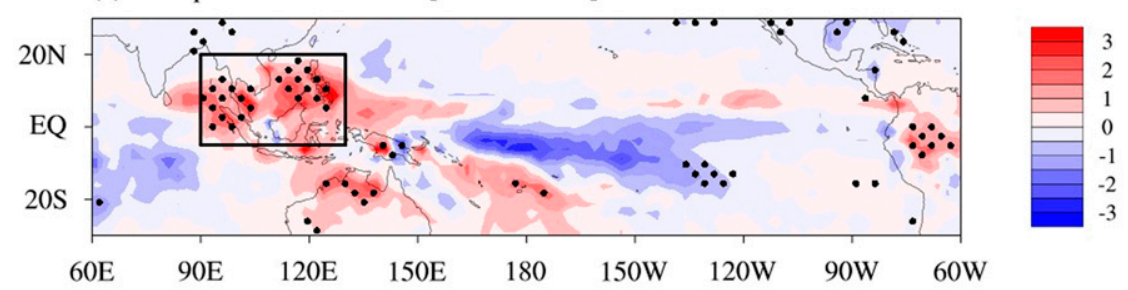

(b) OLR Difference [P2 minus P1]

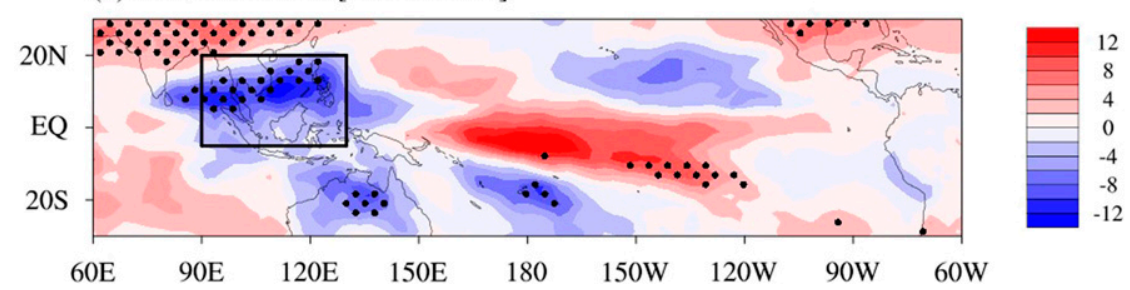

FIG. 7. (a) DJF-mean precipitation difference between two contrasting periods: P2 minus P1 (shading, $\mathrm{mm} \mathrm{day}^{-1}$ ). (b) As in (a), but for the OLR (shading, $\mathrm{W} \mathrm{m}^{-2}$ ). The black dots indicate the areas significant at the $95 \%$ confidence levels. The black rectangle is the area used to compute the zonal mean meridional circulation. 


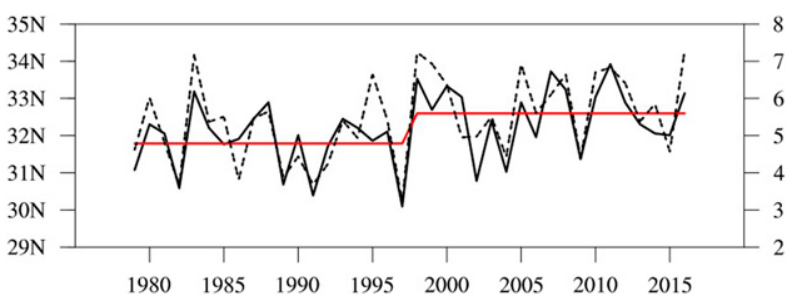

FIG. 8. HCBL index (solid line, left $y$-axis unit: ${ }^{\circ} \mathrm{N}$ ) and WPCA index (dotted line, right $y$-axis unit: $\mathrm{mm} \mathrm{day}^{-1}$ ). The red line denotes the mean value of the HCBL index for the periods before and after the significant regime shifts, based on Rodionov (2004). For determining the regime shift, the following parameters were used: cutoff length $=15$; probability level $=0.1$; and Huber's weight parameter $=1.5$.

convection over the western tropical Pacific contributed to the northward expansion of the local Hadley circulation boundary, subsequently leading to the northward displacement of the EAJS. To support this hypothesis, an idealized experiment was conducted using the LBM, which indicated that the heating over the western tropical Pacific caused the northward shift of the EAJS. Based on these results, it can be concluded that the decadal change in the oceanic and atmospheric mean state across the late 1990s contributed to the decadal change in the relationship between the EAJS and the EAWM.

However, there is a possibility that the weakening of the EAJS-EAWM relationship could be caused by the changes of EAWM variability itself. Figure 10 displays the regressed surface air temperature associated with three indices (EAWMI, EAWMI-1, and EAWMI-2), between P1 and P2. It was found that during $\mathrm{P} 1$, the regression patterns of surface air temperatures associated with the three EAWM indices were similar, characterized by a significant cooling in East Asia (Figs. 10a-c). During P2, in contrast, the patterns of regressed surface air temperatures associated with EAWM indices were significantly different from each other (Figs. 10d-f). This indicates that the EAWM variability, which is associated with lowlevel winds, EAT, and land-sea thermal contrast, changed from $\mathrm{P} 1$ to $\mathrm{P} 2$. A previous study (Wang and Chen 2014) also demonstrated that the EAWM recovered from its weak epoch and reamplified in the mid-2000s, indicating that the variability of EAWM had changed. It is necessary to further examine the influence of EAWM variability on the changes in the EAJS-EAWM relationship. Previous studies have also suggested that the climate system in the Arctic (i.e., sea ice extent and atmospheric circulation) is characterized by remarkable variations over the past two decades (Shimada et al. 2006; Overland et al. 2012; Wu et al. 2012; Wu and Francis 2019). There is a possibility that the change in the Arctic might play a role in changing the atmospheric circulation in the extratropics, including East Asia (Honda et al. 2009; Mori et al. 2014). Therefore, it is necessary to examine the impacts of the Arctic on the changes in the relationship of EAJSEAWM across the late 1990s.

Based on these results, it can be concluded that the EAJSI, which is currently used in climate studies, may not be suitable to explain EAWM variability. Therefore, it may be useful to define a new EAJSI to account for the EAWM variability, based on the change in the oceanic and atmospheric mean state across 1998-99. On the other hand, it is also necessary to use a very highresolution dataset to represent the location of the jet core changes with time as defining the intensity of the EAJS using a fixed region may not be suitable. In addition, the present results also imply that the EAJSI should be carefully defined in a warmer climate because the meridional displacement of the East Asian jet is expected to respond to anthropogenic greenhouse gas emissions (Yin 2005; Miller et al. 2006; Barnes and Polvani 2013). (a) Forcing (atmospheric heating)

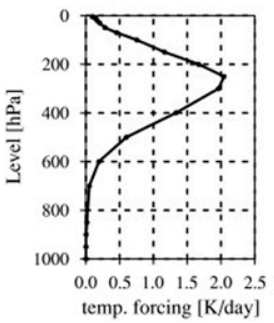

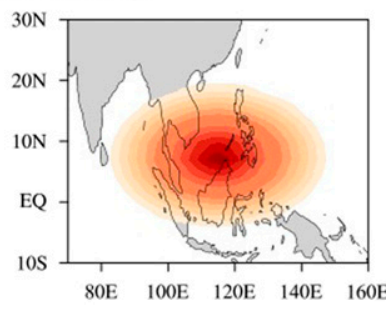

(b) NCEP U200 P1 (red), LBM response (blue)

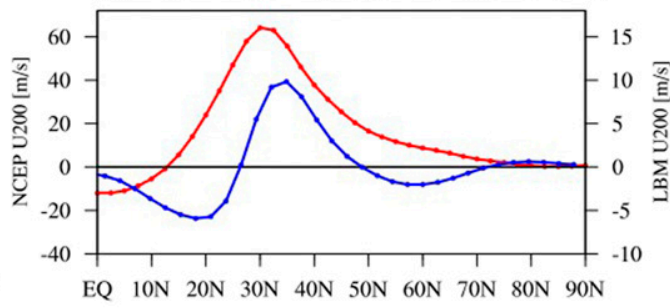

FIG. 9. (a) The vertical profile of atmospheric diabatic heating and its spatial structure prescribed in the LBM experiment. (b) Zonal mean $\left(100^{\circ}-140^{\circ} \mathrm{E}\right)$ zonal wind at $200 \mathrm{hPa}$ in response to the atmospheric heating over the western tropical Pacific in the LBM experiment (blue) and the climatological zonal mean zonal wind at $200 \mathrm{hPa}$ during $\mathrm{P} 1$ (red). Units are $\mathrm{K} \mathrm{day}^{-1}$ and $\mathrm{m} \mathrm{s}^{-1}$ in (a) and (b), respectively. 
(a) $\operatorname{reg}(\mathrm{EAWMI}, \mathrm{SAT})$ in P1

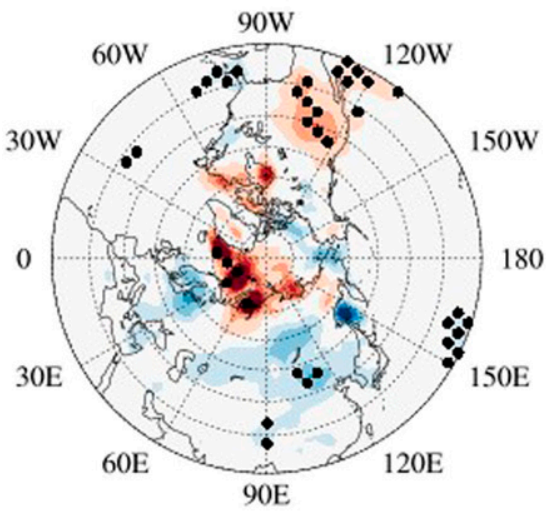

(b) $\operatorname{reg}(\mathrm{EAWMI}-1, \mathrm{SAT})$ in P1

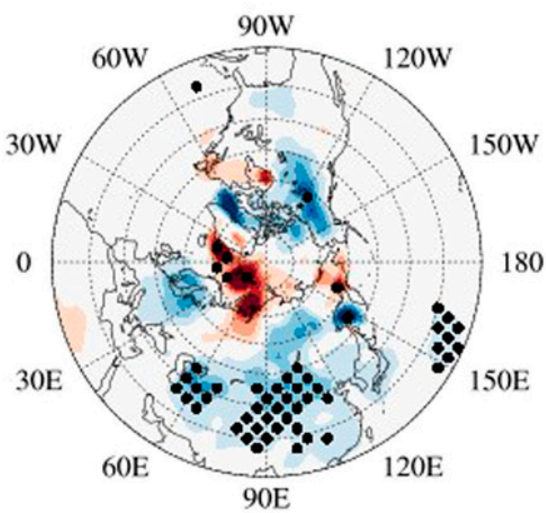

(c) $\operatorname{reg}(\mathrm{EAWMI}-2, \mathrm{SAT})$ in P1

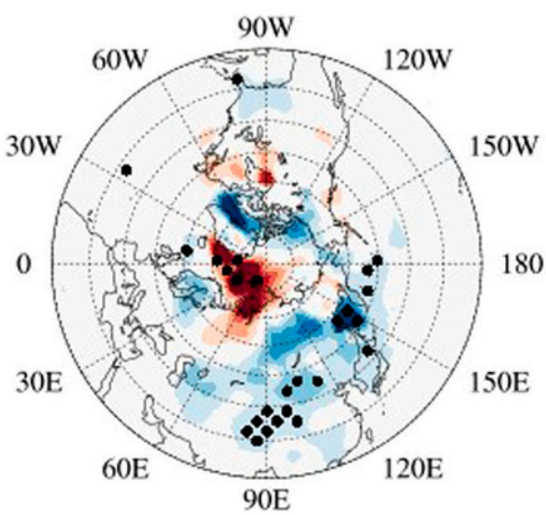

(d) $\operatorname{reg}(\mathrm{EAWMI}, \mathrm{SAT})$ in P2

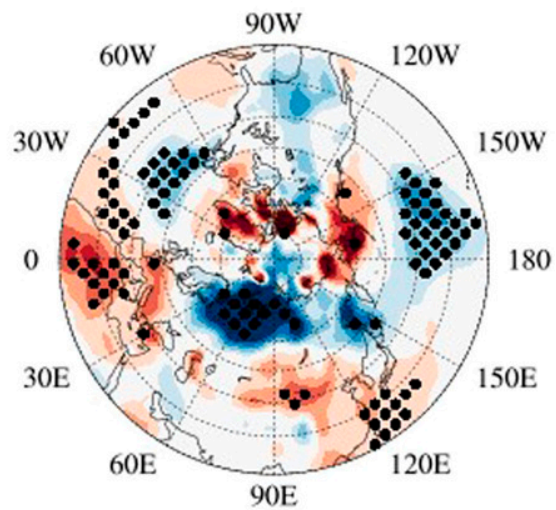

(e) $\operatorname{reg}($ EAWMI-1,SAT) in P2

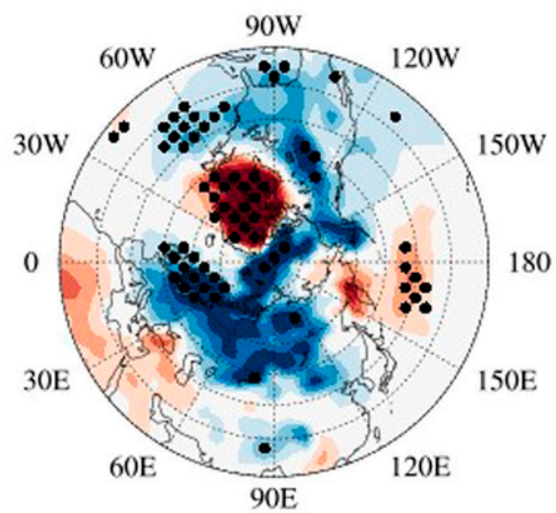

(f) $\operatorname{reg}(\mathrm{EAWMI}-2, \mathrm{SAT})$ in P2

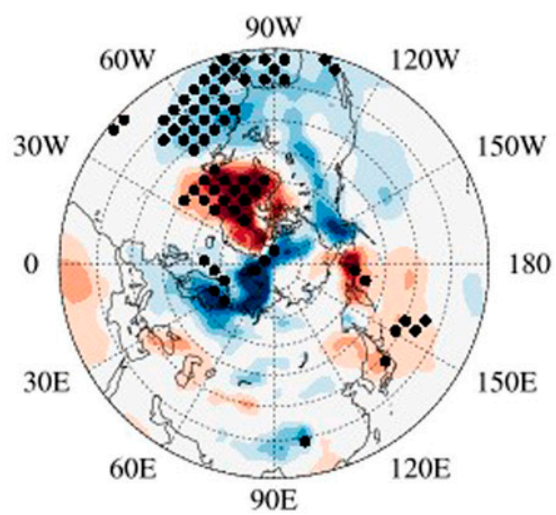

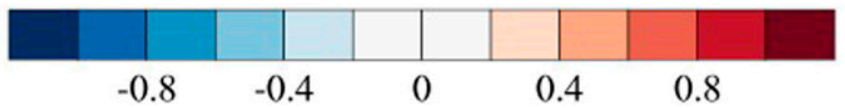

FIG. 10. Regression pattern of DJF-mean surface air temperature (shading, K) associated with the (a) EAWMI, (b) EAWMI-1, and (c) EAWMI-2 during P1. (d)-(f) As in (a)-(c), but for during P2. Black dots indicate the areas significant at the $90 \%$ confidence levels. 
Acknowledgments. This study was supported by National Research Foundation Grant NRF-2018R1A5A1024958.

\section{REFERENCES}

Barnes, E. A., and L. Polvani, 2013: Response of the midlatitude jets, and of their variability, to increased greenhouse gases in the CMIP5 models. J. Climate, 26, 7117-7135, https://doi.org/ 10.1175/JCLI-D-12-00536.1.

Chan, J. C., and C. Li, 2004: The East Asia winter monsoon. East Asian Monsoon, C.-P. Chang, Ed., World Scientific, 54-106, https://doi.org/10.1142/9789812701411_0002.

Chang, C.-P., and K. Lau, 1982: Short-term planetary-scale interactions over the tropics and midlatitudes during northern winter. Part I: Contrasts between active and inactive periods. Mon. Wea. Rev., 110, 933-946, https://doi.org/10.1175/15200493(1982)110<0933:STPSIO > 2.0.CO;2.

—, Y. Zhang, and T. Li, 2000: Interannual and interdecadal variations of the East Asian summer monsoon and tropical Pacific SSTs. Part I: Roles of the subtropical ridge. J. Climate, 13, 4310-4325, https://doi.org/10.1175/1520-0442(2000)013<4310: IAIVOT $>2.0 . \mathrm{CO} ; 2$.

_ Z Z. Wang, and H. Hendon, 2006: The Asian winter monsoon. The Asian Monsoon, B. Wang, Ed., Springer, 89-127.

- Y. Ying, N.-C. Lau, R. H. Johnson, B. Wang, and T. Yasunari, Eds., 2011: The Global Monsoon System: Research and Forecast. 2nd ed. World Scientific, 608 pp., https:// doi.org/10.1142/8109.

Chen, D., H. Wang, J. Sun, and Y. Gao, 2018: Pacific multi-decadal oscillation modulates the effect of Arctic oscillation and El Niño-Southern Oscillation on the East Asian winter monsoon. Int. J. Climatol., 38, 2808-2818, https://doi.org/10.1002/ joc. 5461.

Cressman, G. P., 1984: Energy transformations in the East Asia-west Pacific jet stream. Mon. Wea. Rev., 112, 563-571, https://doi.org/ 10.1175/1520-0493(1984)112<0563:ETITEA > 2.0.CO;2.

Ding, R., K.-J. Ha, and J. Li, 2010: Interdecadal shift in the relationship between the East Asian summer monsoon and the tropical Indian Ocean. Climate Dyn., 34, 1059-1071, https:// doi.org/10.1007/s00382-009-0555-2.

Ding, Y., and T. N. Krishnamurti, 1987: Heat budget of the Siberian high and the winter monsoon. Mon. Wea. Rev., 115, 2428-2449, https://doi.org/10.1175/1520-0493(1987)115<2428: HBOTSH $>2.0 . \mathrm{CO}$; .

_ , and Coauthors, 2014: Interdecadal variability of the East Asian winter monsoon and its possible links to global climate change. J. Meteor. Res., 28, 693-713, https://doi.org/10.1007/ s13351-014-4046-y.

Gong, H., L. Wang, W. Chen, R. Wu, G. Huang, and D. Nath, 2018: Diversity of the Pacific-Japan pattern among CMIP5 models: Role of SST anomalies and atmospheric mean flow. J. Climate, 31, 6857-6877, https://doi.org/10.1175/JCLI-D-17-0541.1.

Ha, K. J., K. Y. Heo, S. S. Lee, K. S. Yun, and J. G. Jhun, 2012: Variability in the East Asian monsoon: A review. Meteor. Appl., 19, 200-215, https://doi.org/10.1002/met.1320.

He, S., and H. Wang, 2013: Oscillating relationship between the East Asian winter monsoon and ENSO. J. Climate, 26, 98199838, https://doi.org/10.1175/JCLI-D-13-00174.1.

Held, I. M., and A. Y. Hou, 1980: Nonlinear axially symmetric circulations in a nearly inviscid atmosphere. J. Atmos. Sci., 37, 515-533, https://doi.org/10.1175/1520-0469(1980)037<0515: NASCIA $>2.0 . \mathrm{CO} ; 2$.
Honda, M., J. Inoue, and S. Yamane, 2009: Influence of low Arctic sea-ice minima on anomalously cold Eurasian winters. Geophys. Res. Lett., 36, L08707, https://doi.org/10.1029/ 2008GL037079.

Hong, C.-C., Y.-K. Wu, T. Li, and C.-C. Chang, 2014: The climate regime shift over the Pacific during 1996/1997. Climate Dyn., 43, 435-446, https://doi.org/10.1007/s00382-013-1867-9.

Huang, B., and Coauthors, 2017: Extended Reconstructed Sea Surface Temperature, version 5 (ERSSTv5): Upgrades, validations, and intercomparisons. J. Climate, 30, 8179-8205, https://doi.org/10.1175/JCLI-D-16-0836.1.

Huang, R., L. Zhou, and W. Chen, 2003: The progresses of recent studies on the variabilities of the East Asian monsoon and their causes. Adv. Atmos. Sci., 20, 55-69, https://doi.org/ 10.1007/BF03342050.

—, J. Chen, L. Wang, and Z. Lin, 2012: Characteristics, processes, and causes of the spatio-temporal variabilities of the East Asian monsoon system. Adv. Atmos. Sci., 29, 910-942, https://doi.org/10.1007/s00376-012-2015-x.

Jhun, J.-G., and E.-J. Lee, 2004: A new East Asian winter monsoon index and associated characteristics of the winter monsoon. J. Climate, 17, 711-726, https://doi.org/10.1175/ 1520-0442(2004)017<0711:ANEAWM>2.0.CO;2.

Jo, H. S., S.-W. Yeh, and C. H. Kim, 2013: A possible mechanism for the North Pacific regime shift in winter of 1998/1999. Geophys. Res. Lett., 40, 4380-4385, https://doi.org/10.1002/ grl.50798.

, — , and B. P. Kirtman, 2014: Role of the western tropical Pacific in the North Pacific regime shift in the winter of 1998/ 1999. J. Geophys. Res. Oceans, 119, 6161-6170, https://doi.org/ 10.1002/2013JC009527.

Kalnay, E., and Coauthors, 1996: The NCEP/NCAR 40-Year Reanalysis Project. Bull. Amer. Meteor. Soc., 77, 437-472, https://doi.org/10.1175/1520-0477(1996)077<0437:TNYRP> 2.0.CO;2.

Kang, I.-S., 1990: Influence of zonal mean flow change on stationary wave fluctuations. J. Atmos. Sci., 47, 141-147, https://doi.org/10.1175/1520-0469(1990)047<0141:IOZMFC> 2.0.CO;2

Kim, M. J., S.-W. Yeh, and R. J. Park, 2016: Effects of sulfate aerosol forcing on East Asian summer monsoon for 19852010. Geophys. Res. Lett., 43, 1364-1372, https://doi.org/ 10.1002/2015GL067124.

Kobayashi, S., and Coauthors, 2015: The JRA-55 Reanalysis: General specifications and basic characteristics. J. Meteor. Soc. Japan, 93, 5-48, https://doi.org/10.2151/jmsj.2015001.

Krishnamurti, T. N., 1961: The subtropical jet stream of winter. J. Meteor., 18, 172-191, https://doi.org/10.1175/15200469(1961)018<0172:TSJSOW $>2.0 . \mathrm{CO} ; 2$.

Lau, K.-M., and M.-T. Li, 1984: The monsoon of East Asia and its global associations-A survey. Bull. Amer. Meteor. Soc., 65, 114-125, https://doi.org/10.1175/1520-0477(1984)065<0114: TMOEAA $>2.0 . \mathrm{CO} ; 2$

Lee, H.-T., A. Gruber, R. G. Ellingson, and I. Laszlo, 2007: Development of the HIRS outgoing longwave radiation climate dataset. J. Atmos. Oceanic Technol., 24, 2029-2047, https:// doi.org/10.1175/2007JTECHA989.1.

Li, Y., and S. Yang, 2010: A dynamical index for the East Asian winter monsoon. J. Climate, 23, 4255-4262, https://doi.org/ 10.1175/2010JCLI3375.1.

Lindzen, R. S., and A. V. Hou, 1988: Hadley circulations for zonally averaged heating centered off the equator. J. Atmos. Sci., 45, 
2416-2427, https://doi.org/10.1175/1520-0469(1988)045<2416: $\mathrm{HCFZAH}>2.0 . \mathrm{CO} ; 2$.

Lyon, B., A. G. Barnston, and D. G. DeWitt, 2014: Tropical Pacific forcing of a 1998-1999 climate shift: Observational analysis and climate model results for the boreal spring season. Climate Dyn., 43, 893-909, https://doi.org/10.1007/ s00382-013-1891-9.

Ma, T., W. Chen, D. Nath, H.-F. Graf, L. Wang, and J. Huangfu, 2018: East Asian winter monsoon impacts the ENSO-related teleconnections and North American seasonal air temperature prediction. Sci. Rep., 8, 6547, https://doi.org/10.1038/ s41598-018-24552-3.

Miao, J., T. Wang, H. Wang, Y. Zhu, and J. Sun, 2018: Interdecadal weakening of the East Asian winter monsoon in the mid1980s: The roles of external forcings. J. Climate, 31, 8985-9000, https://doi.org/10.1175/JCLI-D-17-0868.1.

Miller, R., G. Schmidt, and D. Shindell, 2006: Forced annular variations in the 20th century Intergovernmental Panel on Climate Change Fourth Assessment Report models. J. Geophys. Res., 111, D18101, https://doi.org/10.1029/2005JD006323.

Minobe, S., 2002: Interannual to interdecadal changes in the Bering Sea and concurrent 1998/99 changes over the North Pacific. Prog. Oceanogr., 55, 45-64, https://doi.org/10.1016/S00796611(02)00069-1.

Mori, M., M. Watanabe, H. Shiogama, J. Inoue, and M. Kimoto, 2014: Robust Arctic sea-ice influence on the frequent Eurasian cold winters in past decades. Nat. Geosci., 7, 869-873, https:// doi.org/10.1038/ngeo2277.

Overland, J. E., J. A. Francis, E. Hanna, and M. Wang, 2012: The recent shift in early summer Arctic atmospheric circulation. Geophys. Res. Lett., 39, L19804, https://doi.org/10.1029/ 2012 GL053268.

Park, J.-H., and S.-I. An, 2014: The impact of tropical western Pacific convection on the North Pacific atmospheric circulation during the boreal winter. Climate Dyn., 43, 2227-2238, https://doi.org/10.1007/s00382-013-2047-7.

Park, Y.-H., J.-H. Yoon, Y.-H. Youn, and F. Vivier, 2012: Recent warming in the western North Pacific in relation to rapid changes in the atmospheric circulation of the Siberian high and Aleutian low systems. J. Climate, 25, 3476-3493, https:// doi.org/10.1175/2011JCLI4142.1.

Polyakova, E. I., A. G. Journel, I. V. Polyakov, and U. S. Bhatt, 2006: Changing relationship between the North Atlantic Oscillation and key North Atlantic climate parameters. Geophys. Res. Lett., 33, L03711, https://doi.org/10.1029/ 2005GL024573.

Reiter, E. R., 1963: Jet-Stream Meteorology. University of Chicago Press, $515 \mathrm{pp}$

Rodionov, S. N., 2004: A sequential algorithm for testing climate regime shifts. Geophys. Res. Lett., 31, L09204, https://doi.org/ 10.1029/2004GL019448.

Shimada, K., T. Kamoshida, M. Itoh, S. Nishino, E. Carmack, F. McLaughlin, S. Zimmermann, and A. Proshutinsky, 2006: Pacific Ocean inflow: Influence on catastrophic reduction of sea ice cover in the Arctic Ocean. Geophys. Res. Lett., 33, L08605, https://doi.org/10.1029/2005GL025624.

Song, L., L. Wang, W. Chen, and Y. Zhang, 2016: Intraseasonal variation of the strength of the East Asian trough and its climatic impacts in boreal winter. J. Climate, 29, 2557-2577, https://doi.org/10.1175/JCLI-D-14-00834.1.

Sun, B., and C. Li, 1997: Relationship between the disturbances of East Asian trough and tropical convective activities in boreal winter. Chin. Sci. Bull., 42, 500-504.
Sun, J., S. Wu, and J. Ao, 2016: Role of the North Pacific sea surface temperature in the East Asian winter monsoon decadal variability. Climate Dyn., 46, 3793-3805, https://doi.org/10.1007/ s00382-015-2805-9.

Wang, B., R. Wu, and X. Fu, 2000: Pacific-East Asian teleconnection: How does ENSO affect East Asian climate? J. Climate, 13, 1517-1536, https://doi.org/10.1175/1520-0442(2000)013<1517: PEATHD $>2.0 . \mathrm{CO} ; 2$.

_ Z Z. Wu, C.-P. Chang, J. Liu, J. Li, and T. Zhou, 2010: Another look at interannual-to-interdecadal variations of the East Asian winter monsoon: The northern and southern temperature modes. J. Climate, 23, 1495-1512, https://doi.org/10.1175/ 2009JCLI3243.1.

Wang, H., E. Yu, and S. Yang, 2011: An exceptionally heavy snowfall in Northeast China: Large-scale circulation anomalies and hindcast of the NCAR WRF model. Meteor. Atmos. Phys., 113, 11-25, https://doi.org/10.1007/s00703-011-0147-7.

Wang, L., and W. Chen, 2010: How well do existing indices measure the strength of the East Asian winter monsoon? Adv. Atmos. Sci., 27, 855-870, https://doi.org/10.1007/s00376-0099094-3.

_ monsoon. J. Climate, 27, 2361-2374, https://doi.org/10.1175/ JCLI-D-13-00086.1.

— , and M.-M. Lu, 2017: The East Asian winter monsoon. The Global Monsoon System: Research and Forecast, 3rd ed. C.-P. Chang et al., Eds., World Scientific, 51-61, https://doi.org/ 10.1142/9789813200913_0005.

— W. When, and R. Huang, 2008: Interdecadal modulation of PDO on the impact of ENSO on the East Asian winter monsoon. Geophys. Res. Lett., 35, L20702, https://doi.org/ 10.1029/2008GL035287.

,$- \ldots$, W. Zhou, and R. Huang, 2009: Interannual variations of East Asian trough axis at $500 \mathrm{hPa}$ and its association with the East Asian winter monsoon pathway. J. Climate, 22, 600-614, https://doi.org/10.1175/2008JCLI2295.1.

—, Y. Liu, Y. Zhang, W. Chen, and S. Chen, 2019: Time-varying structure of the wintertime Eurasian pattern: Role of the North Atlantic sea surface temperature and atmospheric mean flow. Climate Dyn., 52, 2467-2479, https://doi.org/ 10.1007/s00382-018-4261-9.

Watanabe, M., and M. Kimoto, 2000: Atmosphere-ocean thermal coupling in the North Atlantic: A positive feedback. Quart. J. Roy. Meteor. Soc., 126, 3343-3369, https://doi.org/10.1002/ qj.49712657017.

Webster, P. J., V. O. Magana, T. Palmer, J. Shukla, R. Tomas, M. Yanai, and T. Yasunari, 1998: Monsoons: Processes, predictability, and the prospects for prediction. J. Geophys. Res., 103, 14 451-14 510, https://doi.org/10.1029/97JC02719.

Wen, C., H.-F. Graf, and H. Ronghui, 2000: The interannual variability of East Asian winter monsoon and its relation to the summer monsoon. Adv. Atmos. Sci., 17, 48-60, https://doi.org/ 10.1007/s00376-000-0042-5.

Wu, B., and J. A. Francis, 2019: Summer Arctic cold anomaly dynamically linked to East Asian heat waves. J. Climate, 32, 1137-1150, https://doi.org/10.1175/JCLI-D-18-0370.1.

— J. E. Overland, and R. D'Arrigo, 2012: Anomalous Arctic surface wind patterns and their impacts on September sea ice minima and trend. Tellus, 64A, 18590, https://doi.org/10.3402/ tellusa.v64i0.18590.

Xie, P., and P. A. Arkin, 1997: Global precipitation: A 17-year monthly analysis based on gauge observations, satellite estimates, and numerical model outputs. Bull. Amer. Meteor. Soc., 
78, 2539-2558, https://doi.org/10.1175/1520-0477(1997)078<2539: GPAYMA $>2.0 . C O ; 2$.

Yang, S., K. Lau, and K. Kim, 2002: Variations of the East Asian jet stream and Asian-Pacific-American winter climate anomalies. J. Climate, 15, 306-325, https://doi.org/10.1175/15200442(2002)015<0306:VOTEAJ > 2.0.CO;2.

Yin, J. H., 2005: A consistent poleward shift of the storm tracks in simulations of 21st century climate. Geophys. Res. Lett., 32, L18701, https://doi.org/10.1029/2005GL023684.
Zhang, Y., K. R. Sperber, and J. S. Boyle, 1997: Climatology and interannual variation of the East Asian winter monsoon: Results from the 1979-95 NCEP/NCAR reanalysis. Mon. Wea. Rev., 125, 2605-2619, https://doi.org/10.1175/1520-0493(1997) 125<2605:CAIVOT>2.0.CO;2.

Zhou, W., C. Li, and X. Wang, 2007: Possible connection between Pacific Oceanic interdecadal pathway and East Asian winter monsoon. Geophys. Res. Lett., 34, L01701, https://doi.org/ 10.1029/2006GL027809. 